\title{
An ANAlysis of FACTORS AfFECTING THE Adoption of Digital Terrestrial Television SERVICES IN THAILAND
}

\author{
Manit Satitsamitpong $^{1}$ and Hitoshi Mitomo ${ }^{2}$ \\ ${ }^{1}$ Graduate School of Global Information and Telecommunication Studies, Waseda \\ University, Japan \\ manitefuji.waseda.jp \\ ${ }^{2}$ Graduate School of Asia-Pacific Studies, Waseda University, Japan \\ mitomo@waseda.jp
}

\section{ABSTRACT}

Digital Terrestrial Television (DTTV) Services is thought to bring many benefits to viewers compared to regular analog televisions. Although many countries around the world introduced DTTV with such benefits in their minds, the rates of DTTV adoption have been slow and many countries have to postpone the analog switch-off date as a consequence. The objective of this study is to examine and understand factors that contribute to consumer intention to adopt DTTV.

In this study we try to evaluate the benefits of consumers' adoption of DTTV services by analyzing consumers' valuations on DTTV's characteristics such as improved video quality, more available TV channels, and other enhanced services against how much they want to pay for a set-top box (STB) or a new digital TV (DTV). We employed a stated preference conjoint analysis method as a way to collect the data from viewers across Thailand. Using such data, we estimated consumers' utilities by applying a discrete choice model to determine important factors and measure their significance. The willingness to pay (WTP) for each factor by consumers will be also calculated. The result of the study will help policy makers to understand Thai TV viewers and provide suggestions on how to promote efficient DTTV adoption strategies.

\section{KEYWORDS}

Digital Terrestrial Television Services, Stated Preference Method, Mixed Logit Model

\section{INTRODUCTION}

Digital television (DTV) has several advantages over analog TV. DTV enables television stations to provide dramatically clearer pictures and better sound quality. By transmitting the information used to make a TV picture and sound as "data bits" like a computer, television stations can also carry more information using digital broadcasting than is currently possible with analog broadcast technology. This means that digital broadcasters can provide more digital channels in the same space, deliver high-definition television service for consumers with HD television sets, offer such basic data services as closed-captioning, electronic program guides and additional languages (spoken or subtitled), and allow other advanced services such as live broadcasting and interactivity functionality. With efficient use of spectrum, the government can utilize freed up parts of the broadcast spectrums for public safety communications and allow some spectrums to be auctioned to companies that will be able to provide consumers with more advanced wireless services in the futures.

With those benefits in minds, many countries around the world had begun broadcasting digital terrestrial television (DTTV) services over-the-air. Currently there are about 10 countries, most of them in Europe, Japan, and the US, which have completed the process of turning off analog

DOI : 10.5121/ijmpict.2013.4202 
terrestrial broadcasting while many had plans to do so or were in the process of a conversion. For example, Australia and South Africa have plans to make a switch over by 2013, India by 2014, Hong Kong and Philippines by 2015.

Although the technical details of such DTTV deployment from those countries which had already completed the projects are widely available, most countries that are planning or implementing right now have had a hard time keeping up with their specified switchover dates due to the slow adoption of the DTTV services. There are number of past researches on what factors affecting the DTTV services adoption in different countries focusing from the view points of government policy and supply side [1-3]. However, few have been done from the consumer perspectives $[4,5]$.

For the present study, we examined consumers' intention to adopt DTTV services via two reception devices, a set-top box (STB) and a new digital TV (DTV) set. In particular, we employed a choice modelling analysis to determine which factors influence consumers' decisions to adopt DTTV after the services become available. The analysis draws data from a conjoint (stated preference) survey in which respondents were asked to choose hypothetical DTTV services taking into account DTTV attributes such as video quality, number of channels available, basic data services, live data broadcasting services, interactive capability, and the price of a STB or a DTV. We then used a mixed logit model to estimate the effects of the attributes that influence consumers' intentions to adopt DTTV services and willingness to pay for those attributes.

This paper is organized as follows. In the next section we briefly provide information about the Thailand television industry and the current situation about digital terrestrial television services in Thailand. Section 3 explains our research methodology, including conjoint survey technique as well as econometric models used in this study. The results and analyses are discussed in Section 4. Finally, the conclusions and implications of the study are presented in Section 5.

\section{An OVERVIEW OF TELEVISION MARKET IN THAILAND}

Thailand has 6 free-to-air terrestrial TV stations, (BEC World Plc. Channel 3, Royal Thai Army Radio and Television Channel 5, Bangkok Broadcasting and Television Company Channel 7, Modernine (Channel 9) by MCOT, National Broadcasting Services of Thailand (NBT), and Thai Public Broadcasting Service (TPBS)), which are based in Bangkok and relayed to all parts of the country through repeaters. Currently, free-to-air TV transmission is based on 625 lines System B (VHF, channels 2-12) or System G (UHF channels 26-60), PAL color, and NICAM-728 stereo and TV channels are transmitted by terrestrial standards with analog system.

Besides the terrestrial television, Thailand has several cable television (CATV), multichannel multipoint distribution service (MMDS), and satellite television providers. TrueVisions UBC is the largest player in the CATV and satellite markets. TrueVisions got concessions from MCOT to operate CATV services in greater Bangkok and encrypted digital satellite TV (DSTV) services throughout the country. Outside Bangkok, hundreds of independent CATV providers offer services in the provinces. Thai TV (TTV) holds a concession from the government's public relation department (PRD) to operate an MMDS service in the Bangkok Metropolitan Area. ASTV and People's Television (PTV) are other free-to-air satellite television networks that offer many channels to their views with specialization in political contents.

In Thailand, the government had trial broadcasts of the digital terrestrial TV services using Digital Video Broadcasting - Terrestrial (DVB-T) in 2001 but currently it is not in operation. In terms of ASEAN, ministers endorsed DVB-T as the standard for the ASEAN member nations at 
the Ninth Conference of the ASEAN Ministers Responsible for Information (AMRI) held in Jakarta Indonesia during May 2007. At the meeting, ASEAN member nations laid down the timeframe for the analog-to-digital switchover from 2015 to 2020 depending on each country's capability and preparation. In 2009 the National Telecommunications Commission (NTC), Thailand telecommunications regulator acting on behalf of the not-yet-established National Broadcasting Commission (NBC) appointed a study group to conduct a feasibility study on technical standard for digital television in Thailand. The study suggested that Thailand should adopt DVB-T standard because it is the most adopted technology in the world which is in congruence to the result in the AMRI meeting. However, the decision about the technology standard still could not be finalized even after the establishment of the national telecommunications and broadcasting commission (NBTC), a single body that oversees both broadcasting and telecommunications industries which replaced the NBC and NTC in October 2011. Finally in May 2012, NBTC chose DVB-T2 as Thailand digital terrestrial television standard over other standards such as ATSC, ISDB-T, or DTMB but the switch-over date has not yet set.

The present study does not deal with the technical issues addressed in the aforementioned study. Rather, this study tries to analyze consumers' adoption via two reception devices when the DTTV services become available using the discrete choice model technique.

\section{Methodology}

\subsection{Stated Preference method}

The study evaluates the benefits of consumers' adoption of the digital terrestrial television (DTTV) services by valuing services reception devices adoption as a proxy. Currently there are two ways to receive the DTTV services.

1. A set-top box (STB). A set-top box for digital television receives and decodes digital transmissions into a form suitable for display on analog television (existing television or CRT TV) sets or other display devices, e.g. computer monitors or projection screens. Analog television sets cannot display digital transmissions on their screens without being connected to such a STB converter. A set-top box, when connected to an analog television set, will usually give viewers an improved signal, better picture quality and multi-channelling. Some STBs may also provide viewers with datacasting services and video, audio and data enhancements but the price will be higher for this type of STBs.

2. A digital TV (DTV). This is a television set which contains all the components necessary to receive and display digital transmissions. Integrated digital television receivers will generally be distinguished by wide screens, high level audio capability and high resolution displays. They will not require a set top box. In addition DTVs can receive all the enhanced services that DTTV services can offer. Therefore, the prices of DTVs are much higher than those of STBs.

Since there is no market price for adopting DTTV services, the study employed stated preference technique as a way of eliciting a consumer's evaluation of DTTV services via the two aforementioned reception devices. Stated preference methods are an attractive tool for researching non-existing situations or products [6]. Stated preference methods have been widely used to study consumers' preferences and measure their willingness to pay for goods and services. The methods involve in asking the respondents to consider one or more hypothetical alternatives and to express their preferences through surveys. A choice-based conjoint analysis, which is one of the stated preference techniques, was employed in this study to construct the surveys. A conjoint analysis has been applied in many research areas such as marketing [7], transportation [8], and telecommunications [9]. In a conjoint analysis, researchers make 
hypothetical bundles using several attributes that describe a product or service and ask respondents to state their preferences from different hypothetical alternatives. The choice-based conjoint has greater advantages over traditional conjoint research as it allows respondents to choose "none" of the proposed alternative, similar to real-world situation. Their responses are then analyzed using statistical techniques.

\subsection{Economic Model}

The study estimates consumer utility using a mixed logit model, which provides a flexible specification for representing the distribution of preferences in the population and the choices of each individual. A mixed logit model does not impose the independence from irrelevant alternatives property of logit and provides flexible substitution patterns across alternatives. The properties implies that relative utility of any two products is independent of the characteristics of products other than the one compared. The mixed logit model has been applied to a wide range of industries including transportation [10], recreation [11], and telecommunications [12].

Utility is derived as follows. Consider a choice among alternatives $J=1,2,3, \ldots, T$. Then the utility that consumer $i$ obtains from choosing alternative $j$ is

$$
U_{i j}=\beta_{i}^{\prime} V_{i j}+\varepsilon_{i j}
$$

where $V_{i j}$ is a vector of variables as a set of attributes when consumer $i$ chooses alternative $j$ and $\varepsilon_{i j}$ is iid extreme value error term. As the distribution of $\beta_{i}$ is unknown, it is common to estimate parameters of the distribution function by assuming parametric probability distribution function. For the present study, we set the coefficients vector $\beta_{i}$ to be normally distributed across the population with mean $\mathrm{b}$ and variance $\mathrm{W}$, i.e., $\beta_{i} \sqcup N(b, W)$. Individual $i$ will choose alternative $j$ if and only if $U_{i j}>U_{i k}$ for any $j \neq k$. With the mixed logit model, we assume $\varepsilon_{i j}$ distributed as independent and identical extreme value distribution and the probability of individual $i$ choosing alternative $j$ that is facing $\beta_{i}$ can be described as

$$
L_{i j}\left(\beta_{i}\right)=\frac{e^{\beta_{i}^{\prime} V_{i j}}}{\sum_{k} e^{\beta_{i}^{\prime} V_{i k}}}
$$

As $\beta_{i}$ is unknown and has a probability distribution, if we let the distribution function of $\beta_{i}$ be $f(\beta)$, then the probability of individual $i$ choosing alternative $j$ out of $J$ alternatives is

$$
P_{i j}=\int \frac{\exp \left(U\left(\beta_{i j}, V_{j}\right)\right)}{\sum_{j=1}^{J} \exp \left(U\left(\beta_{i j}, V_{j}\right)\right)} f(\beta) d(\beta)
$$

A mixed logit probability is a weighted average of the logit formula evaluated at different values of $\beta$, with the weight given by the density. This equation is a multi-dimensional integral so that it does not have a closed-form solution. Therefore, the simulation method is performed to get a mixed logit model estimation.

\subsection{Conjoint Question Design}

The first step in the choice model design is to define the services to be valued in terms of its attributes and values. In this study, the services are the benefits of adopting DTTV services via two types of services reception devices. To select attributes and values of DTTV services, 
previous researches offer good suggestions. The study about standard setting in high-definition television in 1992 by Farrell et al. [2] can provide us with a good initial point. They presented a case study about the past diffusion processes of similar electronic appliances such as the color television and VCR in order to understand what are necessary conditions to the success of transition from analog to digital terrestrial broadcasting for high definition TV (HDTV). Such conditions include (1) availability of HDTV programs, (2) transmission equipment capable of delivering the HDTV signal into the household, and (3) television sets capable of receiving and displaying the HDTV signal. Another study done in the US by [13] analyzes the consumer preferences for different features in digital TV and found that both hardware (picture quality, size of screen, and retail price) and software (availability of the programs) attributes influence the decision to adopt the digital services. They found that the digital TV diffusion rate is slower than expected and one of the reasons for the delay is lacks of TV programs in digital format.

According to the Information and Communications Policy Bureau of Ministry of Internal Affairs and Communications (MIC) [14] of Japan, the annual questionnaire about digital terrestrial broadcasting reports that "picture quality" is one of the reasons why respondents are satisfied with the digital TV services. In addition, respondents also mentioned that they will buy digital TVs if the devices become cheaper. In another study done in Japan [5], the authors argue that digital TV consumers are affected not only by hardware attributes such as picture quality and screen size, but also by software factors such as the number available channels and the switchover date.

Previous studies focus on the features of digital TV without including the benefits that can be obtained from integrating data storage, broadcasting and communication technologies into it. In this study, we included new functionalities to understand how viewers value overall benefits of adopting DTTV services.

Basic data services can be integrated to the digital TV programs, similar to the teletext in analog $\mathrm{TV}$, but with a much greater amount of data in a static manner. Basic data services maybe viewed together with main TV contents or independently. Basic data services include picture and text information which are related to the TV program itself. The viewer can obtain a variety of information including TV program guide, supplement information of a particular TV program, closed-caption, or Braille support functionality.

Live data broadcasting services provides more dynamic and real time information to recent digital TV viewers when compared with basic data services. Live data services expand the range of information services enjoyed by the general public who prefer up-to-date information. Also broadcasters can provide viewers with the useful information in times of emergency. Examples of live data services include live stock updates, exclusive local news reports, live weather information, traffic reports, and natural disaster warning.

Interactive capability makes it possible for information to be sent from the viewer's side using a communications line. For example, while a viewer is watching a television program, he or she can respond to a questionnaire survey, cast a vote for a particular topic, or perform online shopping. Using this function, the viewer can actively participate with the digital TV program rather than passively only obtain one-way information. Moreover, recently there are digital TVs or set-top boxes with broadband internet connectivity that can provide web browsing function similar to the way it can be used on personal computer.

Based on the aforementioned features, we included the attributes and levels for the hypothetical DTTV services in our model and report them in Table 1. Compared with previous studies, the current study analyzes viewers' evaluation on either set-top boxes (STB) or digital TV (DTV)s. Therefore, some attributes can have different values depending on the type of reception devices. In addition, we left out the switch-off date in the model because the date has not been set in Thailand yet. 
Table 1. DTTV's attributes and levels.

\begin{tabular}{|l|l|l|}
\hline \multicolumn{1}{|c|}{ Attribute } & \multicolumn{1}{|c|}{ Explanation } & \multicolumn{1}{|c|}{ Level } \\
\hline Video Quality & $\begin{array}{l}\text { Quality of video that receivers can view } \\
\text { STB: Analog (current quality) and Better (no ghosting or distorting } \\
\text { pictures) } \\
\text { DTV: Standard definition (SD) Improved picture quality (similar to } \\
\text { DVD quality) } \\
\text { and High Definition (HD) (4 times or more better quality than SD } \\
\text { quality) }\end{array}$ & Analog, Better \\
\hline No. of available channels & Number of channels that TV stations provide & 5,15,25,35 \\
\hline Basic services & More added features such as subtitle, Braille, and TV guide & Available, Not available \\
\hline Live Data broadcast & $\begin{array}{l}\text { Real-time information such as stocks, weather, traffic, and natural } \\
\text { disaster updates }\end{array}$ & Available, Not available \\
\hline Interactivity capability & Interactive features such as online buying, giving comments and voting & Available, Not available \\
\hline Set-top box price (Baht) & $\begin{array}{l}\text { Price of receivers } \\
\text { STB: Price of set-top box } \\
\text { DTV: Price of digital TV }\end{array}$ & $\begin{array}{l}1000,2000,3000,4000 \\
10000,30000,50000,70000\end{array}$ \\
\hline
\end{tabular}

a.) Video Quality

This attribute shows the improved video quality that viewers can receive from DTTV services. If they decide to adopt a STB, the level that we use in the choice questions are analog quality (same as the current analog technology) and better than analog (no ghosting or distorting pictures). However, if they decide to adopt a DTV, two levels of video quality are also included, standard definition TV (SDTV) and high definition TV (HDTV).

b.) Number of available channels

This attribute provides another benefit that users can view more channels once DTTV is in services. Currently there are 6 free TV channels terrestrially broadcasting in Thailand. The attribute level ranges from 5 to 35 channels.

c.) Basic data services

This attribute is related to the availability of basic services such as subtitle, Braille language assistance for blind people, and information related to the TV program.

d.) Live data broadcast

Another important feature that DTTV services provides is the live data broadcasting capability such as live traffic update, stock update, or other real-time information. The value for this attribute is either available or not available.

e.) Interactivity capability

Digital broadcasting can also bring an interactive feature to viewers. Viewers can buy things online, make comments, or cast votes if desired. The value for this attribute is also either available or not available.

f.) Price to pay for a STB or a DTV

This is the price that viewers have to pay to receive DTTV services. Depending on the type of receivers that viewers choose, the ranges of prices are different. The price levels for STB are from 1,000 to 4,000 Baht and for DTV are from 10,000 to 70,000 Baht.

Given different attributes and levels above, a large number of unique DTTV services alternatives can be constructed. We employed an experimental design technique [6] using SPSS software to obtain an orthogonal design and came up with 16 alternatives. Then we blocked those alternatives into 4 choice sets which each containing 4 different alternatives. Each choice set, besides having 4 different DTTV services alternatives, contains one option that allows a questionnaire respondent to select none of those alternatives. This "choose none" alternative [10] can be considered a preference to continue using the current analog TV system. An example of a conjoint choice-based question for STB adopter is shown in Figure 1. 


\begin{tabular}{|l|c|c|c|c|c|}
\hline & Option 1 & Option 2 & Option 3 & Option 4 & Option 5 \\
\hline Video Quality & Analog & Analog & $\begin{array}{c}\text { Better } \\
\text { (no ghosting) }\end{array}$ & $\begin{array}{c}\text { Better } \\
\text { (no ghosting) }\end{array}$ & $\begin{array}{c}\text { None of } \\
\text { these }\end{array}$ \\
\cline { 1 - 5 } No. of available channels & 15 & 35 & 5 & 35 & \\
\hline $\begin{array}{l}\text { Basic data services } \\
\text { (subtitle, Braille, TV } \\
\text { guide) }\end{array}$ & Yes & No & No & Yes \\
\hline $\begin{array}{l}\text { Live data broadcast } \\
\text { (live weather, stock, } \\
\text { traffic) }\end{array}$ & No & No & No & Yes & \\
\hline $\begin{array}{l}\text { Interactive capability } \\
\text { (Online buying, vote) }\end{array}$ & 2,000 & 1,000 & 2,000 & 4,000 & \\
\hline Price of Set-top box (Baht) & $\square$ & $\square$ & $\square$ & $\square$ & \\
\hline $\begin{array}{l}\text { Please select one option } \\
\text { that you like the most }\end{array}$ & $\square$ & $\square$ & Yes & \\
\hline
\end{tabular}

Figure 1. Example of a choice-based conjoint question for a STB adopter

\section{RESULTS}

\subsection{Demographic Information}

The choice modelling questionnaire survey was administered in April 2010. Five provinces which represent different regions in Thailand, Bangkok, Khonkaen, Chaingmai, Chonburi, and Songkla, were included in the survey. To collect the data, trained enumerators first explained the basic concept of DTTV services, elaborated the attributes of the DTTV services in order to ensure uniformity of understanding, and taught the questionnaire respondents how to answer the choice questions. In this survey, the respondents were asked to choose a hypothetical DTTV services based on the reception devices they preferred.

Total samples of 500 respondents aged 18 or older were asked to participate in this questionnaire which distributed around the five locations evenly. Of these, 59 of them were eliminated due to incomplete responses. The remaining 441 surveys form the database of this study. In addition to the choice model questions, data on the respondents' demographic information and TV watching behaviors, and awareness on DTTV services were also collected.

The questionnaire's descriptive statistics are presented in Table 2. From the 441 valid samples, $228(52 \%)$ respondents preferred adopting set-top box (STB) as a reception device for DTTV services and 213 (48\%) chose DTV. The distribution of age between STB adopters and DTV adopters in the survey is similar in which majority's ages are from 20 to 39 years old. Both adopter groups have percentage of female respondents more than male. For the income distribution, it can be seen that higher income respondents (more than 20,000 Baht) prefer adopting DTVs while lower income respondents (lower than 20,000 Baht) tend to adopt STBs. Lastly, the levels of educations between two groups are similar. 
International Journal of Managing Public Sector Information and Communication Technologies (IJMPICT) Vol. 4, No. 2, June 2013

Table 2. Respondent descriptive statistics

\begin{tabular}{|c|c|c|c|c|c|}
\hline & \multirow{2}{*}{\multicolumn{2}{|c|}{$\begin{array}{l}\text { Set-top box (STB) } \\
\text { Respondents = } 228\end{array}$}} & \multicolumn{2}{|c|}{ Digital TV (DTV) } \\
\hline & & & & \multicolumn{2}{|c|}{ Respondents $=213$} \\
\hline & & No. & Ratio (\%) & No. & Ratio (\%) \\
\hline \multirow[t]{6}{*}{ Age } & 1. Below 20 years & 9 & 3.9 & 11 & 5.2 \\
\hline & 2. Between 20 and 29 years & 88 & 38.6 & 67 & 31.5 \\
\hline & 3. Between 30 and 39 years & 82 & 36 & 82 & 38.5 \\
\hline & 4. Between 40 and 49 years & 25 & 11 & 32 & 15.0 \\
\hline & 5. Between 50 and 59 years & 20 & 8.8 & 20 & 9.4 \\
\hline & 6. More than 60 years & 4 & 1.8 & 1 & 0.5 \\
\hline \multirow[t]{2}{*}{ Gender } & 1. Male & 102 & 44.7 & 106 & 49.8 \\
\hline & 2. Female & 126 & 55.3 & 107 & 50.2 \\
\hline \multirow{6}{*}{$\begin{array}{l}\text { Monthly } \\
\text { Income }\end{array}$} & 1. $<10,000$ Baht & 83 & 36.4 & 55 & 25.8 \\
\hline & 2. $<20,000 \mathrm{Baht}$ & 79 & 34.6 & 45 & 21.1 \\
\hline & 3. $<30,000$ Baht & 39 & 17.1 & 37 & 17.4 \\
\hline & 4. $<40,000$ Baht & 18 & 7.9 & 24 & 11.3 \\
\hline & 5. $<50,000$ Baht & 6 & 2.6 & 12 & 5.6 \\
\hline & 6. > 50,000 Baht & 3 & 1.3 & 40 & 18.8 \\
\hline \multirow[t]{6}{*}{ Education } & 1. Primary school & 15 & 6.6 & 14 & 6.6 \\
\hline & 2. Secondary school & 39 & 17.1 & 41 & 19.2 \\
\hline & 3. College/Vocational degree & 40 & 17.5 & 30 & 14.1 \\
\hline & 4. Undergraduate & 119 & 52.2 & 100 & 46.9 \\
\hline & 5. Postgraduate & 11 & 4.8 & 23 & 10.8 \\
\hline & 6. Others & 4 & 1.8 & 5 & 2.3 \\
\hline
\end{tabular}

\subsection{Summary of TV usage behaviors and awareness of DTTV services}

Based on results of the survey, we found that the majority of respondents (85\%) still use CRT TVs at home. Also the questionnaire indicates that DTV adopter respondents are currently using flat screen TVs such as LCD and LED TVs more than STB adopter respondents. In general, the video quality in flat screen TV is better than in normal CRT TVs. This implies that DTV adopters value picture quality more than the counterparts.

The respondents were also asked questions about the time spent on activities per day. The results indicate that STB adopters spend about 4 hours per day for watching TV, while the number for STB adopters is 5 hours. While STB adopters spend about 1.4 hours per day to surf the Internet, DTV adopters use more than 2 hours for the Internet daily. Moreover, the survey suggests that DTV adopters are those who at home use broadband Internet more at $40 \%$ compared to only $25 \%$ of STB adopters. In addition, we found that DTV adopters spend about one hour to read newspaper while STB adopters only spend half of the time. These survey results suggest that DTV adopters are interested in retrieving information contents both online and offline more than those STB adopters.

In terms of awareness of DTTV services, about $18 \%$ of the STB adopters have heard about DTTV services, while approximately $31 \%$ of DTV adopters know about the term "DTTV". In addition, for those respondents who knows about DTTV services, DTV adopters understand about different features of DTTV services than STB adopters. This information implies that DTV adopter respondents have more knowledge about DTTV services than STB adopters do. 


\subsection{Estimation results}

In this study, it is assumed that an individual will adopt a particular DTTV services reception device, either a STB or a DTV if the utility of the chosen one is more than the rest of the choices. The utility function of a DTTV services reception device (based on Table 1) is specified as follows:

$$
\begin{aligned}
& U_{i j}=\alpha_{i V I D E O} V_{I D E O}+\alpha_{i \text { CHANNEL }} \text { CHANNEL }_{i j}+\alpha_{i B A S I C} \text { BASIC }_{i j} \\
& +\alpha_{i L I V E} \text { LIVE }_{i j}+\alpha_{i I N T E R A C T I V I T Y} \text { INTERACTIVITY }_{i j} \\
& +\alpha_{i P R I C E} \text { PRICE }_{i j}+\varepsilon_{i j}
\end{aligned}
$$

where

- $\quad U_{i i}$ is the utility of consumer $i$ choosing alternative $j$

- $V I D E O$ is a dummy variable for video quality

- $C H A N K E L_{i j}$ is the number of available channels

- $\quad B A S I C_{i j}$ is a dummy variable for basic data services

- $\quad L I V E_{i j}$ is a dummy variable for the live broadcast feature

- INTERACTIVITY ${ }_{i j}$ is a dummy variable for the interactivity capability

- $\quad P R I C E_{i j}$ is a price variable for receivers (STB or DTV)

- $\quad \alpha_{i j}$ are estimated parameters estimated parameters

- $\varepsilon_{i j}$ is an error term

In the mixed logit model estimation for each individual, all the attributes except prices for STB or DTV were defined to be normally distributed. The estimation was estimated with simulated maximum likelihood with Halton draws using 500 replications. The estimation results from a software package NLOGIT 4.0 are shown in Table 3. The overall fits of the model represented by McFadden pseudo $R^{2}$ were calculated at 0.18 and 0.273 for STB and DTV adopter models respectively, which means that they explain the behavior of respondents to a certain context. Coefficients of all attributes in both models in equation (4) show positive signs except for prices of STB and DTV, and these signs are consistent with our expectations. In addition all estimated coefficients are significant at least $10 \%$ level except live data broadcast and interactivity ability features of STB model, which are although positive but not significant.

The facts that all features estimates in the DTV model are positive and significant mean that DTV adopters value all benefits of DTTV services when choosing to adopt DTVs. In other words, it means that the more features implemented in new DTVs, the more likely that a viewer will adopt such DTVs. In this study, based on the estimations, video quality seems to be the most important feature for DTV adopters. The number of available channels is also vital to the consideration of consumers when deciding to adopt the DTTV services via DTVs. More number of channels means more contents that viewers can receive and therefore this will increase the likelihood that they will adopt DTVs. This information is consistent with the analysis in the previous subsection. Although DTV adopters value the benefit of basic data services in this model, it seems to be the least important feature when compared to other advanced services such as live data broadcasting or interactivity functionality. The negative sign for the price feature suggests that if the price for DTVs is higher, there is less likely chance that users will adopt DTTV services via DTV devices.

For the STB model, the respondents place values highest on video quality and number of available channels features. However the estimates are smaller when compared to those of DTV case. This can be implied that STB adopters value those two features but less important when compared to DTV adopters. In addition, data broadcasting services and interactivity are not significant in this model means that those two features are not important for STB adopters when they make decisions. Rather, basic data services feature is enough for them as it is shown that the estimation of this feature is though small but significant. In general, this implies that simple 
version of STBs that can receive digital signal, view more TV channels, and have basic data features are ideal for viewers to buy STBs. Advanced features such as live data broadcast and interactivity functionality will not increase the likelihood to adopt STBs.

Table 3. Model Estimations

\begin{tabular}{l|l|c|}
\hline \multicolumn{1}{|c|}{ Variables } & $\begin{array}{c}\text { STB } \\
\text { Coefficient (S.E.) }\end{array}$ & $\begin{array}{c}\text { DTV } \\
\text { Coefficient (S.E.) }\end{array}$ \\
\hline Video quality & $0.613^{* *}(.302)$ & $0.910^{* *}(0.413)$ \\
No. of channels & $0.432 *(0.230)$ & $0.607 *(0.358)$ \\
Basic data services & $0.062^{* *}(0.026)$ & $0.020^{*}(0.011)$ \\
Live broadcast & $0.310(0.305)$ & $0.404 *(0.247)$ \\
Interactivity ability & $0.258(0.260)$ & $0.262^{* *}(0.124)$ \\
Price & $-0.0007 * *(0.0002)$ & $-0.00006^{* * * *(0.00002)}$ \\
& & 0.273 \\
McFadden pseudo $R^{2}$ & 0.18 & \\
*** Statistic significant at the 1\% level \\
** Statistic significant at the 5\% level \\
* Statistic significant at the 10\% level
\end{tabular}

In this study, we can measure the mean willingness to pay (MWTP) for each of DTTV services by calculating the ratio of the services attribute coefficient to the price coefficient, given all other parameter coefficients are constant. MWTP is the maximum amount an individual would be willing to pay, sacrifice or exchange to receive a good or services. MWTP measures are widely used to provide information to policy makers regarding the economic value of non-market or environmental goods. Equation 5 shows a simple formula how to calculate MWTP for an attribute of the DTTV services,

$$
\mathrm{MWTPz}_{i}=-\partial \mathrm{U} / \partial \mathrm{z}_{i} * \partial \text { Price } / \partial \mathrm{U}=-\alpha_{z_{i}} / \alpha_{\text {price }}
$$

where $z_{i}$ 's are different benefit features of DTTV services and $\alpha_{z_{i}}$ 's represent coefficient estimates of each benefit features.

Table 4 shows the calculated MWTPs. Note that only those features that are statistically significant in Table 3 are shown. As one can see, the results follow similar tendencies as different features coefficient estimates in Table 3. Since the prices of STBs and DTVs are different, it reflects in the MWTPs for DTV adopters are much higher than those of DTV adopters. For the DTV case, adopters give positive MWTPs to all the features that DTTV services can offer, with video quality and number of available channels features having relatively high values. In the STB case, adopters are willing to pay about 875 Baht for better video quality feature, 617 Baht for more number of available channels and for only 92 Baht for basic data services. However, STB adopters are not willing to pay for advanced features such as live data broadcasting and interactivity functionality. The total MWTPs of 1,584 Baht $(875+617+92)$ represents the amount that individuals would be willing to pay for a STB. This amount is generally below the cost of a normal STB selling in the market. This implies that if policy makers would like individuals to adopt STBs, they might want to subsidize some fund for a fast roll out and an early switch-off date. Since DTV adopters' MWTPs are very high, the policy makers do not have to worry about this case. 
Table 4. Willingness to pay for digital TV attributes

\begin{tabular}{|l|c|c|}
\hline \multicolumn{1}{|c|}{ Variables } & STB & DTV \\
MWTP & MWTP \\
\hline Video Quality & $875.15^{* * *}(235.67)$ & $14493.57 * * *(3557.91)$ \\
No. of channels & $617.44 *(380.05)$ & $9674.03 * *(4252.24)$ \\
Basic data services & $91.59^{* * *}(18.33)$ & $325.38 * *(171.28)$ \\
Live data broadcast & & $6448.09 * *(3305.56)$ \\
Interactive capability & & $3541.81 * *(1827.26)$ \\
\hline
\end{tabular}

\section{CONCLUSIONS AND IMPLICATIONS}

This paper explores the factors that affect consumers' decision on DTTV services adoption via reception devices such as a STB and a DTV. Data for this study was gathered through a stated preference questionnaire survey and evaluated by using the mixed logit model. The results show that, in general, questionnaire respondents' awareness about DTTV services is not high. In addition, we found that low-income viewers tend to adopt STBs as opposed to DTVs. The study also indicated that benefits provided by DTTV services such as better video quality, more available TV channels, basic data services, and advanced data services influence the decision to adopt DTVs. However, advanced services such as live data broadcasting and interactivity ability statistically do not affect STB adopters in making decision. Moreover, willingness to pay (WTP) for a STB is low compared to a normal STB available in the market while WTP for a DTV is much higher.

Based on the results of the study, some implications can be discussed. First, policy makers should try to promote the awareness of DTTV and its services as it is shown that different features increase the likelihood to adopt the services. Second, since WTP is quite low for STB adopters, to stimulate the adoption, policy makers can either give away a simple STB or provide a discount coupon to purchase any STBs of their choices. Vendors of DTTV reception devices can focus on providing cheap and simple STBs while focussing on integrating enhanced services features to DTVs. In addition, not only offering more contents, television stations can also help promote adoption of DTVs by delivering more live data broadcasting services and providing interactivity programs to their viewers.

\section{REFERENCES}

[1] J. Adda and M. Ottaviani, "The transition to digital television*," Economic Policy, vol. 20, pp. 160209, 2005.

[2] J. Farrell and C. Shapiro, "Standard Setting in High-Definition Television," Brookings Papers: Microeconomics pp. 1-93, 1992.

[3] R. Tadayoni and K. E. Skouby, "Terrestrial digital broadcasting: convergence and its regulatory implications," Telecommunications Policy, vol. 23, pp. 175-199, 1999.

[4] S. M. Chan-Olmsted and B.-H. Chang, "Audience knowledge, perceptions and factors affecting the adoption intent of terrestrial digital television," New Media \& Society, vol. 8, pp. 773-800, October $1,2006$.

[5] N. Kasuga, L. Zeng, and M. Shishikura, "An Analysis of Demand for New Devices in the Transition from Terrestrial Broadcasting to Digital-The Case of Digital Televisions in Japan -," Keio Communication Review, vol. 33, pp. 115-131, 2011. 
[6] J. J. Louviere, D. A. Hensher, and J. D. Swait, Stated Choice Methods: Analysis and Applications: Cambridge University Press, 2000.

[7] P. E. Green and V. Srinivasan, "Conjoint-Analysis in Marketing - New Developments with Implications for Research and Practice," Journal of Marketing, vol. 54, pp. 3-19, Oct 1990.

[8] D. A. Hensher, "Measurement of the Valuation of Travel Time Savings," Journal of Transport Economics and Policy, vol. 35, pp. 71-98, 2001.

[9] Y. Kim, "Estimation of consumer preferences on new telecommunications services: IMT-2000 service in Korea," Information Economics and Policy, vol. 17, pp. 73-84, 2005.

[10] C. R. Bhat, "Quasi-random maximum simulated likelihood estimation of the mixed multinomial logit model," Transportation Research Part B-Methodological, vol. 35, pp. 677-693, Aug 2001.

[11] K. Train, "Recreation Demand Models with Taste Differences Over People," Land Economics, vol. 74, pp. 230-239, 1998.

[12] T. Ida and K. Sakahira, "Broadband Migration and Lock-in Effects: Mixed Logit Model Analysis of Japan's High-speed Internet Access Service," Telecommunications Policy, vol. 32, pp. 615-625, 2008.

[13] S. Gupta, D. C. Jain, and M. S. Sawhney, "Modelling the Evolution of Markets with Indirect Network Externalities: An Application to Digital Television," Marketing Science, vol. 18, pp. 396416, 1999.

[14] Information and Communications Policy Bureau, Ministry of Internal Affairs and Communications "Report on Questionnaire Survey with respect to Diffusion of Terrestrial Digital Broadcast," May 2007.

\section{Authors}

Manit Satitsamitpong is a doctoral student at the Graduate School of Global Information and Telecommunication Studies (GITS), Waseda University. He received a BSE in Computer Science and Engineering from University of Pennsylvania, an MBA from University of Illinois at Urbana-Champaign, and an MS from Georgia Institute of Technology. His research interests are in economics and policy issues on information and communications technology (ICT) utilization in developing nations.

Hitoshi Mitomo is Professor of Telecommunications Economics and Policy at the Graduate School of Asia-Pacific Studies (GSAPS) and the Director of the Institute for Digital Society (IDS), Waseda University. He was a visiting Professor at Center for Information and Communication Research, Stockholm School of Economics in 2007. He holds a Master's degree in Environmental Science and a Doctorate in Engineering. $\mathrm{He}$ is a board member of many academic associations including JSICR and International Telecommunications Society. His research has covered a

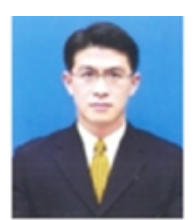
wide range of socio-economic and regulatory issues of ICT deployment and utilization. His current research focuses on the applications of behavioral economics to media access. $\mathrm{He}$ is also interested in microeconomic analysis of telecommunications such as formal analysis of network externalities and pricing telecommunications markets, as well as the measurement of the social and economic impacts of ICT. 